\title{
Long term survival after pulmonary resection for small cell carcinoma of the lung
}

\author{
U S PRASAD, A R NAYLOR, W S WALKER, D LAMB, E W J CAMERON, \\ P R WALBAUM
}

From the Departments of Thoracic Surgery and Pathology, University of Edinburgh

\begin{abstract}
A retrospective review was undertaken of the long term survival of 97 patients with histologically proved small cell carcinoma of the lung resected during the 10 years January 1977December 1986 . Twenty seven patients $(28 \%)$ had stage I disease, $29(30 \%)$ stage II, and $41(42 \%) \stackrel{\infty}{\perp}$ stage III. Patients with stage I and II tumours were managed by resection alone. Patients with stage $ᄋ$ III disease received adjuvant chemotherapy (cyclophosphamide, doxorubicin, and vincristine). Pneumonectomy was undertaken in 75 patients, lobectomy in 21 , and wedge resection in one patient. Three patients died within 30 days of operation. The cumulative five year survival of all patients, $\stackrel{\circ}{\circ}$ irrespective of tumour stage, was $17 \%$. The cumulative five year survival was $35 \%$ for patients with $\mathbb{\Phi}$ stage I disease, $23 \%$ for stage II, and zero for stage III. The median survival for patients with stage III $\overrightarrow{0}$ tumours was 17 months. There was no significant difference in cumulative survival between patients 8 with stage I and II disease. Cumulative survival, however, was significantly better for patients with stage I and II disease than for those with stage III disease. The data suggest that for patients with stage I and stage II disease surgery offers the prospect of long term survival.
\end{abstract}

\section{Introduction}

"It has become standard dogma that surgical
intervention is unwarranted once a diagnosis of small
cell carcinoma of the lung is made. This view may not
be entirely substantiated and there is a growing
recognition that limited disease and extensive disease
behave differently with respect to therapeutic out-
come and this observation may make the reintroduc-
tion of surgical approaches to this disease a reality."
Anderson and Arentzen, 1980 '

Surgical management of patients with small cell carcinoma of the lung fell into disrepute after the report of a Medical Research Council trial was published in $1968^{2}$; the conclusion that surgical resection does not improve long term survival persists to this day. There is evidence, however, that the time has come for a revision of management regimen for patients with small cell carcinoma of the lung, ${ }^{3-5}$ particularly for those with limited or stage I and stage II disease.

The policy of our unit has been to practise resection in patients referred with stage I and II disease, though

Address for reprint requests: Mr U S Prasad, Department of Cardiothoracic Surgery, Royal Infirmary, Edinburgh EH3 9YW.

Accepted 12 July 1989

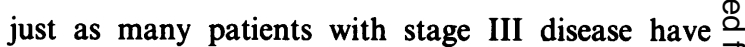
undergone primary resection with adjuvant post- $\overrightarrow{\vec{O}}$ operative chemotherapy during the same period. This 3 study was undertaken in the light of recently reported but smaller studies on the role of surgery, to see if our results justified this approach.

\section{Methods}

A retrospective review was undertaken of 97 con- $\frac{3}{3}$ secutive patients who underwent pulmonary resection of for small cell carcinoma of the lung from January $1977 ₹$ to December 1986. There were 62 men and 35 women 의 (age range 34-80, mean 55 years). Hospital and follow $>$ up data were retrieved from records held in the department of thoracic surgery and the Edinburgh $N$ University department of pathology, where a histo- $\sigma$ logical review was undertaken to ensure that the $\tilde{O}$ diagnosis of small cell carcinoma was correct in every $\mathbb{\omega}^{N}$ case. Pathological and TNM staging was performed $\bar{O}$ by correlation of the operative and subsequent histo- 0 logical findings.

Surgical selection from the 127 patients who were $\stackrel{?}{?}$ actually referred for operation during the 10 years was 0 based on assessment of fitness and the absence of widespread metastatic disease in patients with stage III $\stackrel{\mathbb{D}}{\stackrel{D}{~}}$ disease. Although the policy of the surgical unit has $\mathbb{\mathbb { Q }}$ been to advocate pulmonary resection for all patients 
with stage I and II disease, this is not the policy of all the referring physicians. The true number of stage $I$ and II patients treated in Edinburgh during the 10 years would therefore have been greater than the 127 referred for surgical advice. Patients were routinely investigated by posteroanterior and lateral chest radiograrhy, bronchoscopy, barium swallow, and diaphragmatic screening. Mediastinoscopy and mediastinotomy were not performed routinely even in patients with a preoperative diagnosis of small cell carcinoma. Radioisotope, ultrasound, and computed tomography investigations for extrathoracic metastases were carried out when indicated by abnormal clinical or biochemical findings. Thirty of the 127 patients referred for surgery did not proceed to thoracotomy because of widespread metastases or poor general fitness.

Management was by pulmonary resection and clearance of ipsilateral metastatic lymph nodes in all patients with stage I or II disease. No patient with stage I or II disease received adjuvant chemotherapy or radiotherapy. Patients with stage III disease received adjuvant chemotherapy two weeks after surgery-initially only those with extrathoracic metastases, but 14 in addition had chemotherapy when no intrathoracic metastases were evident after resection. They received cyclophosphamide $\left(1 \mathrm{~g} / \mathrm{m}^{2}\right)$, doxorubicin $\left(40 \mathrm{mg} / \mathrm{m}^{2}\right)$, and vincristine $\left(1 \mathrm{mg} / \mathrm{m}^{2}\right)$ at three weekly intervals for three cycles. Responders received further cycles at monthly intervals for up to one year or until they relapsed.

Survival was defined as the time from operation to death or, in the case of survivors, the last clinical review. Actuarial five year survival was estimated by Kaplan-Meier's product limit method. ${ }^{6}$ Deaths within 30 days of operation were included in the estimation of survival data.

\section{Results}

The results of pathological staging are shown in table

Table 1 Tumour stage in the 97 patients

\begin{tabular}{llc}
\hline $\begin{array}{l}\text { UICC } \\
\text { classification }\end{array}$ & $\begin{array}{l}\text { TNM } \\
\text { classification }\end{array}$ & $\begin{array}{l}\text { No of } \\
\text { patients }\end{array}$ \\
\hline \multirow{2}{*}{ Stage I } & T1 N0 M0 & 3 \\
& T1 N0 M0 & 22 \\
T2 N0 M0 & 2 \\
Stage II & T2 N1 M0 & 29 \\
& T2 N2 M1 & 6 \\
\multirow{2}{*}{ Stage III } & T3 N1 M0 & 2 \\
& T3 N2 M0 & 20 \\
& T3 N2 M1 & 11 \\
& T3 N2 M2 & 2
\end{tabular}

UICC-Union Internationale Contre le Cancer; TNM-tumour, nodes, metastases.

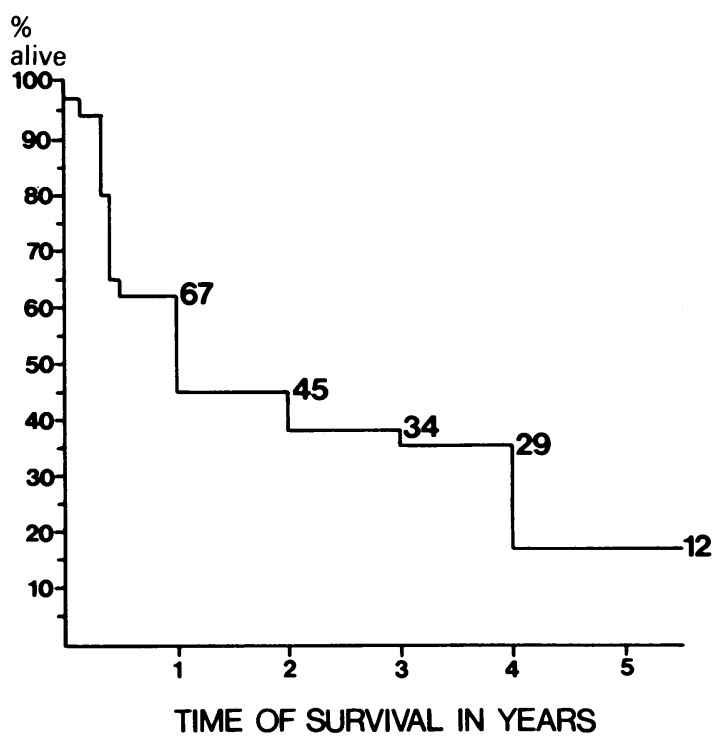

Fig 1 Cumulative survival for the 97 patients undergoing pulmonary resection for small cell carcinoma of the lung. The figures indicate the number of patients entering each time interval during follow up.

1. Twenty seven patients had stage I disease according to the Union Internationale Contre le Cancer (UICC) classification, 29 had stage II disease, and 41 stage III. Nineteen patients of the 41 with stage III disease had preoperative evidence of extrathoracic metastases. In this group of patients pulmonary resection was undertaken as a debulking procedure before adjuvant chemotherapy.

A positive preoperative diagnosis had been made at bronchoscopy in $71(73 \%)$ patients; the remainder had a definitive diagnosis made after resection. Most tumours were in the left lung (67 of the 97) and the upper lobes (65). Sixty three tumours were central and 34 peripheral. Surgical management was by pneumonectomy in 75 patients (eight intrapericardial) and lobectomy in 21 ; one patient underwent segmental resection. In the 41 patients with metastatic nodal disease there were 70 hilar deposits, three interlobar, 14 subcarinal, 12 subaortic, and 12 paratracheal, and four in a pulmonary ligament.

Three of the 97 patients died within 30 days of operation as a consequence of myocardial infarction, pulmonary embolism, and bronchopneumonia consequent on a bronchopleural fistula respectively. A further 25 patients $(26 \%)$ suffered substantial nonfatal complications (19 bronchopneumonia, five bronchopleural fistula, and one pulmonary embolus).

The cumulative five year survival for the study group as a whole was $16.8 \%$ (fig 1). When the data were analysed according to UICC staging (fig 2), $35.4 \%$ with stage I disease, $22.6 \%$ with stage II, but 


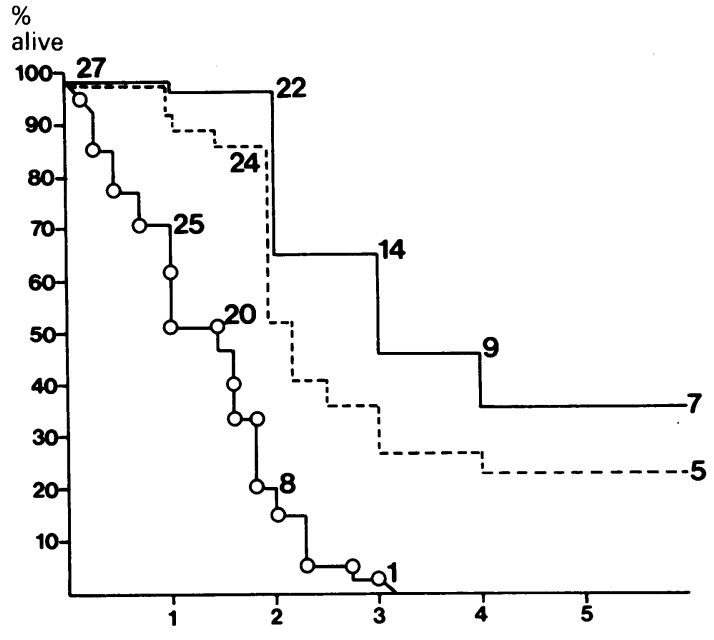

TIME OF SURVIVAL IN YEARS

Fig 2 Cumulative survival for patients undergoing pulmonary resection for small cell carcinoma of the lung divided on the basis of UICC staging. The figures indicate the number of patients entering each time interval during follow up. - Stage I (27 patients); ----- stage II (29 patients); $\mathrm{O}-\mathrm{O}$ stage III (41 patients).

none with stage III survived five years. The median survival for patients with stage III disease undergoing resection and receiving adjuvant chemotherapy was 17 months. There was no significant difference in cumulative survival between patients with stage I and with stage II disease treated by surgical resection alone. Patients with limited disease (stage I and II) had a significantly better cumulative five year survival than stage III patients $(p<0.01)$. Metastatic disease accounted for all deaths during follow up, cerebral metastases being the most frequently identified. No patient with $\mathrm{N} 2$ disease survived beyond three years from operation.

\section{Discussion}

The management of patients with small cell carcinoma of the lung is controversial and the long term results poor (table 2). Many of the current attitudes to management date back to the Medical Research Council trial, which concluded that long term survival was better in patients receiving radiotherapy than those having surgical resection, ${ }^{2}$ and in consequence the role of surgery has declined. ${ }^{7}$ Radical radiotherapy has now been replaced by chemotherapy as the primary mode of management, ${ }^{8}$ the former now being used in the prophylaxis and management of metastatic disease, particularly in the brain. ' With a combined modality approach, a survival rate of $42 \%$ has been reported at one year and of $15 \%$ at two years. ${ }^{9}$

In this study resection alone was undertaken in all
Prasad, Naylor, Walker, Lamb, Cameron, Walbaum $\underset{x}{ }$

Table 2 Long term survival in patients with limited small cell carcinoma of the lung in published series and this study

\begin{tabular}{|c|c|c|c|c|c|}
\hline \multirow[b]{2}{*}{ Survival } & \multicolumn{5}{|c|}{ Mode of management (\% of patients surviving) } \\
\hline & $\begin{array}{l}R T \\
\text { alone }\end{array}$ & $\begin{array}{l}R T+ \\
C T\end{array}$ & $\begin{array}{l}C T \\
\text { alone }\end{array}$ & Surgery & $\begin{array}{l}\text { Surgery } \\
+C T\end{array}$ \\
\hline $1 \mathrm{y}$ & $30^{9}$ & $42^{9}$ & $38^{9}$ & $\begin{array}{l}24^{2} \\
62^{14}\end{array}$ & \\
\hline $2 y$ & $11^{9}$ & $15^{9}$ & $7^{9}$ & $\begin{array}{l}96^{*} \\
52 \dagger\end{array}$ & $\begin{array}{l}76^{10} \ddagger \\
56^{10} \S\end{array}$ \\
\hline $5 y$ & $11^{2}$ & & & $\begin{array}{c}6^{2} \\
23 \dagger \\
25^{5} \\
35^{*} \\
36^{14}\end{array}$ & $\begin{array}{l}24^{15} \\
59^{3}\end{array}$ \\
\hline
\end{tabular}

patients with stage I and II disease. Our five year: survival rate compares favourably with the results of $\frac{\Phi}{-}$ other management regimens (table 2) and, in par- $\vec{\bullet}$ ticular, with the recent data of Karrer et al. ${ }^{10}$ On the basis of the long term survival in 112 patients, these authors concluded that initial surgical resection foll-o owed by intensive chemotherapy was the appropriate therapeutic approach in patients with limited disease. Their survival figures for patients undergoing resec- $\frac{}{\Phi}$ tion and postoperative randomisation to one of two chemotherapeutic regimens were $76 \%$ at 24 monthso응 and $62 \%$ at 36 months for patients with stage I disease and $56 \%$ and $50 \%$ for patients with stage II disease. ${ }^{10}$ This compares with $96 \%$ and $65 \%$ for stage I patients and $52 \%$ and $36 \%$ for stage II patients at the same time points in our own patients treated by surgery alone. We found no significant difference in the cumulative five year survival between the stage I and 3 stage II patients treated by resection alone, and there was also no difference in survival in these categories between patients treated by pneumonectomy and by lobectomy.

Direct comparison of published data (table 2) $\rightarrow$ however, is often misleading. Most studies contain a small number of unselected patients and the stage of 0 disease in the patients undergoing treatment is often not clear. Most patients included in table 2 were classified as having "limited" disease, though the ${ }^{\omega}$ survival in UICC staged patients is indicated where known. Our conclusions from the data obtained in this? study suggest that resection offers the best chance of long term survival in patients with stage $I$ and $\mathrm{II}^{-}$ disease. Whether or not this is further improved with $\frac{T}{6}$ adjuvant postoperative chemotherapy remains to be seen.

These results must, however, be taken in the context $\mathbb{\mathscr { D }}$ of the overall problem of small cell carcinoma of the 
lung. During the 10 years of the study the Edinburgh Lung Cancer Group would have expected to see 1800 small cell cancers from a population of $900000 .{ }^{\text {"I }}$ The relatively small number (127) actually referred for surgical resection reflects the current view of most physicians that small cell carcinoma of the lung is not a surgical condition. Our impression, however, is that many more patients would have been eligible for resection given a different view of the possible benefits of surgical intervention.

The main problem concerns the management of patients with stage III disease. Though advocating primary surgical resection and adjuvant chemotherapy in patients with $\mathrm{T} 1, \mathrm{~T} 1 \mathrm{~N} 1$, and $\mathrm{T} 2$ lesions, Shield $e t a^{3}$ advise against surgical resection for patients with other TNM classifications (five year survival 4-9\%). Our experience is similar to theirs for stage III patients (median survival 17 months) and reflects the aggressive nature of this disease (median survival for untreated patients with extensive disease five weeks). ${ }^{12}{ }^{13}$ In a comprehensive review of the role of radiotherapy and chemotherapy in patients with extensive disease, Salazar and Creech recognise that, although some patients may derive benefit from aggressive combined regimens, this may be at the expense of severe toxicity in some patients. ${ }^{9}$

We have used resection as a debulking procedure in our patients with stage III disease before adjuvant chemotherapy. The median survival of 17 months exceeds the median survival for both limited stage disease (12 months) ${ }^{16}$ and diffuse disease (5-9 months) $)^{17-19}$ reported for chemotherapy alone and indeed for chemotherapy and radiotherapy, 9-16 months. ${ }^{182021}$ Debulking may therefore confer some survival value in these patients and merits further investigation.

This work was presented at the Society of Thoracic and Cardiovascular Surgeons of Great Britain and Ireland, September 1987.

\section{References}

1 Anderson RW, Arentzen CE. Symposium on nonthoracic cardiovascular surgery: carcinoma of the lung. Surg Clin North Am 1980;60:793-814.

2 Fox W, Scadding JG. Medical Research Council comparative trial of surgery and radiotherapy for primary treatment of small-celled or oat-celled carcinoma of bronchus: ten year follow-up. Lancet 1968;ii:925-7.

3 Shields TW, Higgins GA, Matthews MJ, Keehn RJ. Surgical resection in the management of small cell carcinoma of the lung. Surg Clin North Am 1987;67:1103-15.

4 Meyer JA. Surgical treatment of lung carcinoma: indications for surgical treatment in small cell carcinoma of the lung. Surg Clin North Am 1987;67:1103-15.

5 Shore DF, Paneth M. Survival after resection of small cell carcinoma of the bronchus. Thorax 1980;35:819-22.
6 Kaplan EL, Meier P. Non-parametric estimation from incomplete observations. American Statistical Association Journal 1958;53:457-8.

7 Merkle NM, Toomes H, Drings P, Vogt-Moykopf I. Problems of oat cell carcinoma: surgical resection. In: Delarue ND, Eschapasse H, eds. International trends in thoracic surgery. Philadelphia: Saunders, 1985: 190-8.

8 Cohen MH. Small cell lung cancer: restrained optimism. Int J Radiat Oncol Biol Phys 1980;6:1119-20.

9 Salazar OM, Creech RH. "The state of the art" towards defining the role of radiation therapy in the management of small cell bronchogenic carcinoma. Int $J$ Radiat Oncol Biol Phys 1980;6:1103-17.

10 Karrer K, Shields TW, Denck H, Hrabar B, VogtMoykopf I, Salzer GM. The importance of surgical and multimodality treatment for small cell bronchial carcinoma. J Thorac Cardiovasc Surg 1989;97:168-76.

11 Edinburgh Lung Cancer Group. Patients presenting with lung cancer in south east Scotland. Thorax 1987;42:853-7.

12 Roswit B, Patno ME, Rapp R, et al. The survival of patients with inoperable lung cancer. A large-scale randomized study of radiation therapy versus placebo. AJR 1968;90:688-97.

13 Wolf J, Patno ME, Roswit B, D'Esopo N. Controlled study of survival of patients with clinically inoperable lung cancer treated with radiation therapy. $\mathrm{Am} \mathrm{J} \mathrm{Med}$ 966;40:360-7.

14 Higgins GA, Shields TW, Keehn RJ. The solitary pulmonary nodule: ten year follow up of Veterans Administration-Armed Forces Cooperative study. Arch Surg 1975;110:570-5.

15 Shepherd FA, Ginsberg RJ, Feld R, et al. Reduction in local recurrence and improved survival in surgically treated patients with small cell lung cancer. $J$ Thorac Cardiovasc Surg 1983;86:498-506.

16 Hansen M, Osterlind K, Dombrenowsky P, Sorenson S, Hansen HH. Cyclic alternating chemotherapy in small cell bronchogenic carcinoma. Results of a randomised trial of 222 patients [abstract]. In: Proceedings of American Society of Clinical Oncology 1983:C784.

17 Hansen HH, Hansen M. A comparison of 3 and 4 drugs combination chemotherapy of advanced small cell anaplastic carcinoma of the lung. Ann Intern Med 1978;89:177-81.

18 Dombernowsky P, Hansen HH, Hansen M. Treatment of small cell anaplastic bronchogenic carcinoma. Results from 2 randomised trials. In: Proceedings of Second World Conference on Lung Cancer. Amsterdam: Excerpta Medica, 1980:149.

19 Cohen MH, Creaven PJ, Fossieck BE. Intensive chemotherapy with small cell bronchogenic carcinoma. Cancer Treat Rep 1977;61:349-51.

20 Williams C, Alexander M, Glatstein EJ. Role of radiation therapy in combination with chemotherapy in extensive small cell cancer of the lung: a randomised study. Cancer Treat Rep 1972;61:1427-31.

21 Perez CA, Einhorn L, Oldman RK, et al. Preliminary report on a randomised trial of radiotherapy to the thorax in limited stage small cell carcinoma of the lung treated with multiagents chemotherapy [abstract]. In: Proceedings of American Society of Clinical Oncology 1983:C742. 